\title{
The Status of the Commercial Production of Potted Orchid Around the World
}

\author{
J eff B ritt \\ The Rod M CLellan Co., 914 South Claremont St., San M ateo, CA 94402-1834
}

W orldwide potted orchid production continues to increase, driven by five key factors: 1) increasing popularity of orchids in Europe, Asia, and the U nited States; 2) improvements in propagation techniques and practices; 3) acceptance by growers of potted orchids as profitable crop; 4) improved plant performance, especially in hybrid phalaenopsis orchids (PhalaenopsisBlume.); and 5 ) segmentation of the supply chain. These factors have led to the emergence of potted orchids as a category in the world's largest consumer markets. Further expansion is almost certain within these markets through the first decade of the new millennium, with new opportunities predicted in areas following trends established by other plant categories, e.g., roses (R osa L.).

The increase in orchid popularity in Europe was clearly demonstrated in 1999, when potted phalaenopsis orchids became the number three potted plant sold through D utch auctions, after Ficus benjamina L. and african violets (Saintpaulia Wendl). In Japan, orchid sales have increased despite an economy protracted recession. In the U nited States, orchids have emerged as new and popular new plant category, promoted and championed by celebrities like $M$ artha Stewart, image retailers like Smith \& H awken, and glitzy e-commerce companies like Garden.com. Plants, which could only be purchased through a limited number of outlets, are now sold through grocery stores, chain discount stores, and home improvement centers. The public's appetite for potted orchids seems to be almost insatiable.

I mprovements in and acceptance of orchid propagation techniques have led to a greatly increased supply of quality orchid plants. Propagation of orchids had been one of the greatest obstacles to increasing worldwide production since they require a long period of in vitro culture. The development of tissue culture techniques for other popular plant cultivars, the training of technicians to perform the technique, and the building of larger facilities for in vitro culture have all combined to increase the production of orchid plants. This propagation increase is directly responsible for the increase potted orchid culture.

The increased supply of orchid plants have found growers as potted orchid plants have demonstrated themselves a viable economic crop. In Europe especially, growers have been carefully and systematically educated on the profitability of growing potted orchids, and this has stimulated gradual and steady increases in production. In the $U$ nited States, growers seeking more profitable use of their greenhouses are 
turning to potted orchids as an alternative to foliage houseplants and cut flower crops.

The improvement of orchid cultivars propagated for potted culture, especially in phalaneopsis orchids, has increased the profitability for growers, and stimulated purchase by consumers. Whether through improved breeding programs or through new, sophisticated tissue culture techniques, propagators are supplying growers with plants having shorter bench time with less losses. B reeding has improved plants size, growth habit, flower longevity, temperature tolerance, and consumer appeal.

Supply chain segmentation has improved world wide potted production. The old, vertically integrated orchid business has been replaced by specialists: breeders, propagators, finishers, and marketers/ distributors. Successful specialists focus on their segment of the supply chain and add value by improving product quality, lowering cost, and expanding the market for potted orchids.

Future developments are likely to center on increased production of potted orchids, improved and standardized plant size and quality, penetration into new geographic markets, and the extension of the orchid category into related hard goods and care products. The one thing that is certain is that potted orchids will continue their steady conquer of world markets. 